\title{
Pengaruh Perbedaan Status Pegawai Terhadap Kinerja Pegawai di Kantor Kesejahteraan Rakyat Kabupaten Mandailing Natal
}

\author{
Desi Rani, Sudarman \\ Jurusan Ilmu Administrasi Negara Fakultas Ilmu Sosial dan Ilmu Politik Universitas Teuku Umar, Aceh, Indonesia
}

\begin{tabular}{|c|c|}
\hline ARTICLE INFORMATION & A B S T R A C T \\
\hline $\begin{array}{l}\text { Received: September 02, } 2021 \\
\text { Revised: September 23, } 2021 \\
\text { Accepted: October 14, } 2021 \\
\text { Available online: October 31, } 2021\end{array}$ & \multirow{5}{*}{$\begin{array}{l}\text { The current } 4.0 \text { revolution requires all lines to continue to transform in providing excellent service to the } \\
\text { community. This is due to the development of science and increasingly sophisticated technology. Competition } \\
\text { between fields is getting more challenging, including the government, highly highlighted for public consumption. } \\
\text { All must be able to maintain the existence of their institutions to survive in the current } 4.0 \text { era. The purpose of } \\
\text { this study was to examine the effect of differences inemployee status on employee performance at the Office of the } \\
\text { People's Welfare of Mandailing Natal Regency. This study is a quantitative study with a research population of } \\
\text { fewer than } 100 \text { people, so all } 30 \text { employees were used as research samples. The data analysis technique used is a } \\
\text { simple linear regression (t) test. After statistical tests were carried out, it was obtained that the employment } \\
\text { status had a positive regression coefficient value of } 36,053 \text {. The results of this positive coefficient value indicate } \\
\text { that employment status has a positive effect on employee performance. All statements of employment status and } \\
\text { performance variables have a value of } 0.33 \text {, meaning that the performance indicators, namely, work quality, } \\
\text { quantity, timeliness, effectiveness, and independence, are all good. Employees who havehigher employment status } \\
\text { will have better performance in service compared to non-status employees. }\end{array}$} \\
\hline KEYWORDS & \\
\hline Employee Status, Performance & \\
\hline CORRESPONDENCE & \\
\hline $\begin{array}{l}\text { Nama: Sudarman } \\
\text { E-mail: sudarman@utu.ac.id }\end{array}$ & \\
\hline
\end{tabular}

\section{PENDAHULUAN}

Revolusi 4.0 saat ini, menuntut semua bidang untuk dapat bertransformasi agar meningkatkan pelayanan prima terhadap masyarakat, khususnya disebuah organisasi ataupun di instansi (Africa et al., 2020). Hal ini disebabkan oleh ilmu pengetahuan yang semakin berkembang dan teknologi yang semakin canggih (Akseleran.co.id). Persaingan antara semua bidang semakin ketat khususnya di bidang pemerintahan yang sangat disoroti untuk menjadi konsumsi publik. Setiap bidang harus dapat menjaga eksistensi dari instansinya untuk tetap dapat bertahan di era 4.0 saat ini.

Suatu instansi pasti mengalami kenaikan dan bahkan penurunan dalam melakukan pengembangan pelayanannya terhadap masyarakat. Hal ini dilihat dari kinerja pegawai dalam memberikan pelayanan terhadap masyarakat (Anjanarko \& Kurlilah, 2020). Sebab, kinerja pegawai adalah hasil dari akibat yang dilakukan atau tidak dilakukan oleh pegawai (Mathis dan Jackson, 2002) dalam (Murti \& Srimulyani, 2013).

Salah satu faktor yang dapat mempengaruhi kinerja adalah status kepegawaian (Anjanarko \& Kurlilah, 2020). Dalam suatu instansi dan yang lebih universal diucap adalah dunia kepegawaian tidak seluruh pekerja ataupun pegawai memiliki status kepegawaian yang sama, sehingga timbul hak ataupun kewajiban yang berbeda- beda. Pemakaian sebutan kepegawaian, pekerja, dan tenaga kerja pada hakikatnya secara yuridis tidak memiliki makna yang berbeda terkait dengan kehadirannya di dalam suatu instansi, hanya saja berbeda area penggunaanya (Wijaya, 2016).

Kantor Kesejahteraan Rakyat Mandailing Natal memiliki peran penting dalam menyukseskan visi dan misi Bupati khususnya di bidang keagamaan dalam rangka meningkatkan kualitas umat dalam beribadah, melestarikan syiar-syiar agama Islam serta menigkatkan pengetahuan dalam dakwah. Dari visi https://doi.org/10.35308/jpp.v7i2.4078 dan misi tersebut, Kesra memiliki beberapa kegiatan yaitu melaksanakan Musabaqah Tilawatil Qur'an, pemilihan Da'i cilik putra-putri, lomba azan cilik, lomba nasyid untuk kaum ibu-ibu, bantuan dana terhadap tempat ibadah serta pemberian dana intensif kepada guru-guru MDTA,TPA, PONTREN, guru magrib mengaji, nazir masjid, dan anak yatim setiap Tahunnya.

Untuk dapat menyukseskan visi dan misi Bupati tersebut dibutuhkan sumber daya manusia (pegawai) untuk dapat mencapai tujuan instansi secara maksimal untuk dapat mendorong kinerja dari pegawai. Masalah sumber daya manusia ini harus diperhatikan karena merupakan kunci dari berkembangnya suatu instansi dengan jumlah pegawai yang memadai dan kinerja yang baik. Cara menghadapi atau memecahkan masalah sumber daya manusia didalam instansi pada dasarnya yang memiliki wewenang dan tanggung jawab dalam penempatan, pemindahan, pengembangan, serta pemberhentiannya adalah pimpinan instansi. Namun, sering kali kebijakan dari pimpinan bersifat pribadi. Akibatnya, banyak yang berasumsi bahwa sumber daya manusia diatur atas dasar hak prerogatif pimpinan. Sementara itu, evaluasi kinerja untuk pegawai sangat berarti serta berguna dalam mengenali prestasi kerja serta langkah-langkah positif yang akan dilakukan kedepannya dalam rangka meniti karir.

Kantor Kesejahteraan Rakyat Kabupaten Mandailing Natal tidak juga terlepas dari situasi dan kondisi tersebut. Pegawai Negeri Sipil (PNS) dan pegawai honorer memilki cara yang berbeda dalam memberikan pelayanan terhadap masyarakat. Pegawai Negeri Sipil (PNS) di Kantor Kesejahteraan Rakyat sudah mampu memberikan pelayanan prima terhadap masyarakat dibandingkan dengan pegawai honorer. Padahal semua pegawai harus selalu memberikan pelayanan terbaik serta memperbaiki kinerja untuk mencapai sasaran kerja yang sudah disepakati dan tercantum dalam tugas dan fungsinya.

Attribution-ShareAlike 4.0 International. Some rights reserved 
Dari beberapa hasil penelitian terdahulu (Mursyidin, 2020) menyimpulkan bahwa Pengaruh Pemberian Penghargaan Terhadap Kinerja Pegawai Di Dinas Kebudayaan Dan Pemuda Kabupaten Aceh Barat dalam kategori tinggi yang menandakan bahwa pemberian penghargaan perlu dilakukan oleh instansi. Adapun, menurut (Abdullah,\& Azis, 2019) menyimpulkan bahwa status pegawai berpengaruh terhadap kinerja pegawai secara positif serta signifikan melalui kepuasan kerja pegawai di UPTD Puskesmas Kajuara, hasil ini dilihat dari nilai thitung sebesar 3,686 yang lebih besar dari tabel 1,669.

Penelitian ini penting dilakukan agar perbedaan status kepegawaian di dalam sebuah instansi tidak dijadikan sebuah alasan untuk tidak memberikan pelayanan terbaik terhadap masyarakat. Hipotesis penelitian ini yaitu; Ho = Tidak ada pengaruh status pegawai terhadap kinerja pegawai dan $\mathrm{Ha}=$ Ada pengaruh status pegawai terhadap kinerja pegawai.

Berdasarkan pemaparan di atas penulis tertarik untuk melakukan penelitian tentang "Pengaruh Perbedaan Status Pegawai Terhadap Kinerja Pegawai di Kantor Kesejahteraan Rakyat Kabupaten Mandailing Natal".

\section{METODE}

Metode yang dilakukan dalam penelitian ini adalah kuantitatif. Tempat dan lokasi dari penelitian ini adalah di Kantor Kesejahteraan Rakyat Mandailing Natal yang berlokasi di Komplek Perkantoran Payaloting, Parbangunan Kabupaten Mandailing Natal. Waktu penelitian ini dilakukan pada bulan Maret-Juli 2021.

Populasi adalah jumlah keseluruhan subjek penelitian (Arikunto, 2009). Adapun populasi dalam riset ini adalah seluruh pegawai Kantor Kesejahteran Rakyat Mandailing Natal dengan jumlah Pegawai Negeri Sipil (PNS) 8 orang, dan pegawai honorer 22 orang. Teknik pengumpulan data yang dilakukan adalah dengan menggunakan kuisioner.

Sebelum melakukan uji statistik untuk pengolahan data yang sudah terkumpul terlebih dahulu data kuisioner dikelompokkan dan diolah secara manual. Kemudian, dilakukan pentabelan dengan cara memasukkan skor (angka). selanjutnya, tabel data tabulasi akan dianalisis. Tabulasi data akan diolah dengan bantuan spss 16.0 untuk dilakukan pengujian reliabilitas. Analisis data dilakukan dengan menggunakan metode analisis regresi linier sederhana untuk menguji ada atau tidak adanya pengaruh dari status kepegawaian terhadap kinerja pegawai.

\section{Status Pegawai}

Status pegawai merupakan kondisi yang dapat membedakan satu pegawai dengan pegawai lainnya di sebuah instansi (Hendrajana et al., 2017). Sedangkan, pegawai ialah seseorang yang bekarja tetap atau kontrak dan memiliki kesepakatan kerja tertulis atau tidak tertulis untuk melakukan pekerjaan tertentu yang sudah ditetapkan oleh pihak pemberi kerja (Robbins, 2006)

Jadi, ditarik kesimpulan dari defenisi di atas bahwa status pegawai adalah peran atau jabatan seorang yang bekerja pada sesuatu kesatuan organisasi, baik itu sebagai pegawai tetap ataupun tidak tetap bertujuan untuk memenuhi kebutuhan hidupnya. Pada dasarnya, status pegawai dapat dibedakan menjadi 3 yaitu; karyawan tetap, karyawan kontrak dan outsourcing (Hendrajana et al., 2017). Akan tetapi, dalam penelitian hanya terdapat 2 status pegawai yaitu, pegawai negeri sipil dan pegawai honorer.

\section{Pegawai Negeri Sipil}

Undang-Undang Nomor 43 Tahun 1999 tentang pokokpokok kepegawaian dalam jurnal (Fay, 1967) menyatakan bahwa Pegawai Negeri Sipil merupakan tiap-tiap warga negara Republik Indonesia yang telah memenuhi ketentuan yang sudah ditetapkan dan diangkat oleh pejabat yang berwewenang dan dibebankan tugas, serta di gaji berdasarkan peraturan perundang-undangan yang berlaku. Jadi, defenisi dari Pegawai Negeri Sipil adalah seseorang yang bekerja untuk negara baik itu sebagai Pegawai Negeri Sipil ataupun pegawai pemerintahan yang memiliki perjanjian kerja dan disertai dengan tugas dalam suatu tanggung jawab jabatan di sebuah pemerintahan yang memiliki gaji dan diatur oleh peraturan perundang-undangan.

\section{Pegawai Honorer (Pegawai Tidak Tetap)}

Definisi pegawai honorer (pegawai tidak tetap) yang tercatat dalam Peraturan Pemerintah No 48 Tahun 2005 yaitu: tenaga honorer merupakan seseorang yang diangkat pemerintah kepegawaian atau pejabat lain untuk melaksanakan tugas tertentu di dalam instansi atau yang penghasilannya menjadi beban dari Anggran Pendapatan dan Belanja Negara atau dari Anggran Pendapatan dan Belanja Daerah.

Variabel status pegawai memiliki indikator menurut (Singarimbun, 1995 dalam skiripsi Haridsyah (2018).

1. Pegawai dibagi menjadi dua yaitu; PNS dan pegawai honorer (pegawai tidak tetap)

2. Usia; yaitu anggapan terhadap umur seseorang dalam hal ini berkaitan dengan tugas-tugas dan aktivitas yang dilaksanakan ataupun amanah pekerjaan dari instansi mencakup nilai efisiensi, daya guna, dan produktivitas.

3. Jenis kelamin; yaitu anggapan orang terhadap jenis kelamin yang berkaitan dengan tipe pekerjaan yang dilakukan dalam oraganisasi atau kesesuain tipe kelamin dengan pekerjaanya.

4. Tingkat pendidikan; yaitu kesesuaian tingkat pendidikannya atau peletihan yang diikutinya dengan pekerjaan yang sekarang.

5. Masa kerja; yaitu waktu atau periode bekerja yang sudah dialami oleh seseorang semasa kerjanya. Hal ini mencakup nilai senioritas, jabatan, dan keikutsertaanya dalam organisasi.

\section{Kinerja Pegawai}

Kinerja adalah salah satu item yang dapat dijadikan sebagai tolak ukur untuk melihat seberapa besar kualitas atau kemampuan pegawai dalam menjalankan tugas yang dibebankan terhadapnya. Adapun indikator yang dapat mengukur kinerja pegawai ( Robbins dan judge, 2015 dalam (Jeneponto, 2020) secara individu terdapat 5 indikator yaitu;

a. Kualitas kerja

Kualitas kerja dapat diukur dari persepsi pegawai terhadap kualitas pekerjaan atau tugas yang di bebankan serta potensi, keterampilan dan kemampuan yang dimilikinya.

b. Kuantitas

Kuantitas adalah hasil dari aktivitas yang dapat diselesaikan oleh pegawai seperti jumlah unit dan jumlah siklus. 
c. Ketepatan waktu

Ketepatan waktu adalah tingkat aktivitas yang di selesaikan diawal waktu dan dilihat dari hasil akhir (output) maksimal dan waktu yang tersedia untuk aktivitas lain.

d. Efektivitas

Efektivitas adalah meningkatkan hasil dari setiap unit dalam penggunaan sumber daya seperti (tenaga, uang, teknologi, dan bahan baku).

e. Kemandirian

Kemandirian adalah tingkat komitmen kerja pegawai, tanggung jawab dalam menjalankan fungsi kerjanya.

\section{HASIL DAN PEMBAHASAN \\ Karakteristik Responden}

Penelitian ini menggunakan 30 responden dengan 30 kuisioner yang sudah dibagikan kemudian sudah dijawab oleh responden untuk diolah lebih lanjut, karakteristik responden diuraikan sebagai berikut:

1. Karakteristik Responden Berdasarkan Status Pegawai

Jumlah data responden berdasarkan status pegawai di Kantor Kesejahteraan Rakyat Kabupaten Mandailing Natal.

Tabel 1. Identitas Responden Berdasarkan Status Pegawai

\begin{tabular}{lll}
\hline Status Pegawai & Frekuensi & Persentase \\
\hline Pegawai Negeri Sipil & 8 & $27 \%$ \\
Pegawai Honorer & 22 & $73 \%$ \\
Total & 30 & $100 \%$ \\
\hline
\end{tabular}

Sumber: data primer diolah peneliti

Berdasarkan tabel 1.1 menunjukkan bahwa $73 \%$ responden adalah berstatus pegawai honorer dan $27 \%$ berstatus Pegawai Negeri Sipil (PNS)

2. Karakteristik responden berdasarkan jenis kelamin

Jumlah data responden berdasarkan jenis kelamin di Kantor Kesejahteraan Mandailing Natal.

Tabel 2. Jenis Kelamin Responden Pegawai Negeri Sipil

\begin{tabular}{lll}
\hline Jenis Kelamin & Frekuensi & Persentase \\
\hline Laki- Laki & 5 & $62,5 \%$ \\
Perempuan & 3 & $37,5 \%$ \\
Total & 8 & $100 \%$
\end{tabular}

Sumber: data primer diolah

Berdasarkan tabel 2, menunjukkan bahwa 62,5\% responden Pegawai Negeri Sipil (PNS) berjenis kelamin lakilaki dan $37,5 \%$ perempuan.

Tabel 3. Jenis Kelamin Responden Pegawai Honorer

\begin{tabular}{lll}
\hline Jenis Kelamin & Frekuensi & Persentase \\
\hline Laki- Laki & 14 & $64 \%$ \\
Perempuan & 8 & $36 \%$ \\
Total & 22 & $100 \%$ \\
\hline
\end{tabular}

Sumber: data primer diolah peneliti

Berdasarkan tabel 3, menunjukkan bahwa identitas responden pegawai honorer $64 \%$ adalah berjenis kelamin lakilaki dan 36\% perempuan. Bersumber dari data primer diolah dapat disimpulkan bahwa responden rata-rata adalah laki-laki.

\section{Uji Validitas}

Validitas merupakan suatu ukuran yang menunjukkan tingkat-tingkat kevalidan atau keaslian suatu instrumen yang ditentukan. Menurut (Pangarso \& Susanti, 2016), suatu instrumen yang memiliki validitas tinggi maka dikatakan instrumen valid. Menurut menyatakan bahwa instrumen yang memiliki validasi rendah maka di katakan kurang valid. Pengujian validasi ini dilakukan dengan menggunakan SPSS 16.0 .

Pengambilan keputusan uji validasi menggunakan batasan r tabel dengan signifikasi 5\% atau 0,05. Untuk pengambilan keputusan uji validitas dapat dilihat melalui: Jika $R_{\text {hitung }}>R_{\text {tabel, }}$ maka pernyataan tersebut valid.

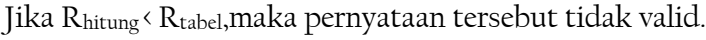

Tabel 4. Hasil uji validitas Pegawai Negeri Sipil

\begin{tabular}{cccc}
\hline $\begin{array}{c}\text { No } \\
\text { Pertanyaan }\end{array}$ & $\begin{array}{c}\text { Corrected Item- } \\
\text { totalCorrelation }\end{array}$ & R tabel & Keterangan \\
\hline 1 & 0.888 & 0.33 & Valid \\
2 & 0.888 & 0.33 & Valid \\
3 & 0.888 & 0.33 & Valid \\
4 & 0.888 & 0.33 & Valid \\
5 & 0.888 & 0.33 & Valid \\
\hline
\end{tabular}

Sumber: data primer diolah peneliti

Dari hasil pengujian pada tabel 4, diperoleh bahwa hasil dari pernyataan untuk mengukur variabel Pegawai Negeri Sipil, memiliki Rhitung lebih besar dari Rtabel untuk sampel 30 orang, hasil ini menandakan bahwa seluruh pernyataan yang digunakan untuk mengukur variabel kinerja pegawai adalah valid.

Tebel 5. Hasil uji validitas Pegawai Honorer

\begin{tabular}{cccc}
\hline $\begin{array}{c}\text { No } \\
\text { Pertanyaan }\end{array}$ & $\begin{array}{c}\text { Corrected Item-total } \\
\text { Correlation }\end{array}$ & $\begin{array}{c}\mathrm{R} \\
\text { tabel }\end{array}$ & Keterangan \\
\hline 1 & 0.777 & 0.33 & Valid \\
2 & 0.432 & 0.33 & Valid \\
3 & 0.664 & 0.33 & Valid \\
4 & 0.761 & 0.33 & Valid \\
5 & 0.745 & 0.33 & Valid \\
\hline
\end{tabular}

Sumber: data primer diolah peneliti

Dari hasil pengujian dilakukan pada tabel 5, diperoleh bahwa hasil dari pernyataan untuk mengukur variabel Pegawai Negeri Sipil, memiliki $\mathrm{R}_{\text {hitung }}$ lebih besar dari $\mathrm{R}_{\text {tabel }}$ untuk sampel 30 orang, hasil ini menandakan bahwa seluruh pernyataan yang digunakan untuk mengukur variabel kinerja pegawai adalah valid.

Tabel 6. Hasil uji validitas kinerja pegawai

\begin{tabular}{cccc}
\hline $\begin{array}{c}\text { No } \\
\text { Pertanyaan }\end{array}$ & $\begin{array}{c}\text { Corrected Item- } \\
\text { total Correlation }\end{array}$ & $\begin{array}{c}\mathrm{R} \\
\text { tabel }\end{array}$ & Keterangan \\
\hline 1 & 0.492 & 0.33 & Valid \\
2 & 0.543 & 0.33 & Valid \\
3 & 0.409 & 0.33 & Valid \\
4 & 0.417 & 0.33 & Valid \\
5 & 0.758 & 0.33 & Valid \\
6 & 0.437 & 0.33 & Valid \\
7 & 0.614 & 0.33 & Valid \\
8 & 0.458 & 0.33 & Valid \\
9 & 0.666 & 0.33 & Valid \\
10 & 0.433 & 0.33 & Valid \\
\hline
\end{tabular}

Sumber; SPSS 16.0 
Dari hasil pengujian pada tabel 6, diperoleh bahwa hasil dari pernyataan untuk mengukur variabel Pegawai Negeri Sipil, memiliki $\mathrm{R}_{\text {hitung }}$ lebih besar dari $\mathrm{r}$ tabel untuk sampel 30 orang, hasil ini menandakan bahwa seluruh pernyataan yang digunakan untuk mengukur variabel kinerja pegawai adalah valid.

\section{Uji Reliabilititas}

Uji reliabilititas ini bertujuan untuk melihat hasil kuesioner ini memang benar dan dapat dipercaya untuk alat pengumpulan data. Pengujian ini dilakukan mengacu pada nilai Alpha yang dihasilkan melalui SPSS 16.0. Kriteria suatu instrument dikatakan reliabel dengan teknik ini, apabila koefisien reliabilitas (rll) > 0,6. Jika instrument ukur mempunyai nilai (rll) < 0,6 maka alat ukur tersebut tidak reliable (Sofyan, 2013).

Tabel 7. Hasil Uji Reliabiltas Pegawai Negeri Sipil

\begin{tabular}{cc}
\hline Cronbach's Alpha & N of Items \\
\hline .785 & 5 \\
\hline
\end{tabular}

Sumber: data primer diolah peneliti

Dari hasil pengujian pada tabel 7 , diperoleh bahwa hasil dari reliabel variabel Pegawai Negeri Sipil yang valid adalah 0,785. Mengacu pada metode Sofyan koefisien reliabilitas 0,785 > 0,6. Sehingga, instrumen yang digunakan dapata dikatakan reliabel.

Tabel 8. Hasil Uji Reliabilitas Pegawai Honorer

\begin{tabular}{cc}
\hline Cronbach's Alpha & N of Items \\
\hline
\end{tabular}

\section{.685} 5

Sumber: data primer diolah peneliti

Dari hasil pengujian pada tabel 8, menggunakan aplikasi SPSS diperoleh bahwa hasil dari reliabilitas 5 instrumen adalah 0.685 . Mengacu pada metode Sofyan koefisien reliabilitas 0.685 > 0,6. Sehingga, instrumen yang digunakan dapat dikatakan reliabel atau konsisten.

Tabel 9. Hasil Uji Reliabilitas Kinerja Pegawai

\begin{tabular}{cc}
\hline Cronbach's Alpha & N of Items \\
\hline .796 & 10 \\
\hline
\end{tabular}

Sumber: data primer diolah peneliti

Dari hasil pengujian pada tabel 9, menggunakan aplikasi SPSS diperoleh bahwa hasil dari reliabilitas 10 instrumen adalah 0,796. Mengacu pada metode Sofyan koefisien reliabilitas $0,796>0,6$. Sehingga, instrumen yang digunakan dapat dikatakan reliabel atau konsisten.

\section{Uji Regresi linear sederhana}

Uji statistik t (parsial) digunakan untuk mengetahui ada atau tidaknya pengaruh secara signifikan antara masing-masing variable independen, tingkat signifikansi 0,05 . Menguji setiap koefisien regresi dikatakan signifkan apabila nilai mutlak thitung t tabel maka hipotesis nol (Ho) ditolak dan hipotesis alternatif (Ha) diterima atau variabel independen secara individual mempengaruhi variabel independen Kemudian untuk mengetahui besarnya pengaruh masing-masing variabel independen secara parsial terhadap variabel dependen adalah sebagai berikut.

Tabel 10. Hasil Uji Regresi Linear Sederhana

\begin{tabular}{cccccc}
\hline Model & $\begin{array}{c}\text { Unstandardized } \\
\text { Coefficients }\end{array}$ & $\begin{array}{c}\text { Standardized } \\
\text { Coefficients }\end{array}$ & t & Sig. \\
\hline B & Std. Error & Beta & & \\
\hline (Constant) & 36.053 & 2.359 & & 15.282 & .000 \\
\hline $\begin{array}{c}\text { Status } \\
\text { kepegawaian }\end{array}$ & .207 & .126 & .344 & 2.636 & .007 \\
\hline
\end{tabular}

a. Dependent Variable: kinerja pegawai

Sumber: data primer diolah peneliti

Dari tabel 10, dengan memperhatikan angka yang berada pada kolom Unstandardized Coefficient Beta, maka dapat disusun persamaan regresi sederhana yaitu, variabel status kepegawaian memiliki nilai koefisien regresi yang positif yaitu sebesar 36.053. Nilai koefisien yang positif ini menunjukkan status kepegawaian berpengaruh positif terhadap kinerja pegawai. Sedangkan terlihat bahwa thitung koefisien status kepegawaian adalah 2.636 sedangkan $t_{\text {tabel }}$ bisa dihitung pada tabel $\mathrm{t}$-test, dengan $\alpha=0,05 \mathrm{dan} \mathrm{df}=30$. Hasil ini didapat dari rumus $\mathrm{df}=\mathrm{n}-1$, di mana $\mathrm{n}$ adalah jumlah sampel (30) - 1 sehingga didapat $t$ tabel adalah 1.699. thitung $>t$ tabel $(5.2 .636>1.699)$ maka $\mathrm{H}_{0}$ ditolak dan $\mathrm{H}_{\mathrm{a}}$ diterima. Hal ini menandakan bahwa Ada pengaruh status pegawai terhadap kinerja pegawai. Dari Uji Regresi linear sederhana ini didapatkan bahwa perbedaan status pegawai dapat diukur dan dilihat dari seberapa tinggi kinerja seseorang serta status pegawai yang diterimanya.

Setelah dilakukan uji statistik diperoleh status kepegawaian memiliki nilai koefisien regresi yang positif yaitu sebesar 36.053. Hasil nilai koefisien yang positif ini menunjukkan status kepegawaian berpengaruh positif terhadap kinerja pegawai. Dari seluruh pernyataan variabel status kepegawaian dan kinerja memiliki nilai 0,33 yang menandakan bahwa indikator-indikator yang digunakan semuanya adalah baik. Pegawai yang memiliki status kepegawaian lebih tinggi (PNS) akan memiliki kinerja yang lebih baik dibandingkan dengan pegawai honorer dalam meningkatkan pelayanan terhadap masyarakat.

Pengaruh positif status kepegawaian terhadap kinerja pegawai ini menandakan bahwa Pegawai Negeri Sipil(PNS) di Kantor Kesejahteraan Rakyat Kabupaten Mandailing Natal sudah mampu memberikan pelayanan terbaik terhadap masyarakat melalui kinerja yang dilakukannya.

\section{Uji Determinan}

Uji determinan adalah pengujian yang dilakukan untuk mengetahui seberapa besar kemampuan dari variabel bebas dalam menjelaskan indikator dari variabel terikatnya.

Tabel 1l. Uji Determinan

\begin{tabular}{ccccc}
\hline Model & $\mathrm{R}$ & $\mathrm{R}$ & Adjusted \\
Square & R Square & $\begin{array}{c}\text { Std. Error } \\
\text { of the } \\
\text { Estimate }\end{array}$ \\
\hline
\end{tabular}




\begin{tabular}{lllll}
\hline 1 & $.544^{\mathrm{a}}$ & .118 & .194 & 1.764 \\
\hline
\end{tabular}

a. Predictors: (Constant), Status kepegawaian Sumber: data primer diolah peneliti

Berdasarkan tabel 11 , diperoleh bahwa nilai $\mathrm{R}=0,544$ hal ini menunjukkan bahwa pengaruh antara status kepegawaian terhadap kinerja pegawai sebesar 54\% yang artinya memiliki pengaruh cukup kuat. Nilai adjusted R Square sebesar 0.194 atau (20\%). Hal ini menunjukkan bahwa persentase status kepegawaian terhadap kinerja pegawai sebesar 20\%, sedangkan sisanya sebesar $80 \%$ dipengaruhi oleh variabel lain diluar variabel yang diteliti.

\section{KESIMPULAN}

Bersumber dari hasil penelitian yang dilakukan di Kantor Kesejahteraan Mandailing Natal, maka diperoleh kesimpulan bahwa:

1. Status kepegawaian berpengaruh positif terhadap kinerja pegawai yang menandakan bahwa pegawai yang memiliki status kepegawaian lebih tinggi akan memiliki kinerja yang baik dalam memberikan pelayanan terhadap masyarakat.

2. Hasil uji regresi linier sederhana menunjukkan bahwa variabel status kepegawaian memiliki nilai koefisien regresi yang positif yaitu sebesar 36.053. Nilai koefisien yang positif ini menunjukkan status kepegawaian berpengaruh positif terhadap kinerja pegawai. Sedangkan terlihat bahwa thitung koefisien status kepegawaian adalah 2.636 sedangkan $\mathrm{t}$-tabel bisa dihitung pada tabel $\mathrm{t}$-test, dengan $\alpha=0,05$ dan $\mathrm{df}=30$. Hasil ini didapat dari rumus $\mathrm{df}=\mathrm{n}-1$, dimana $\mathrm{n}$ adalah jumlah sampel (30) - 1 sehingga didapat t-tabel adalah 1.699. thitung t tabel $(5.2 .636>1.699)$ maka HO diterima dan Ha ditolak. Hal ini menandakan bahwa Ada pengaruh yang kuat antara status pegawai terhadap kinerja pegawai.

3. Hasil uji determinan diperoleh bahwa nilai $\mathrm{R}=0,544$ hal ini menunjukkan bahwa pengaruh antara status kepegawaian terhadap kinerja pegawai sebesar 54\% yang artinya memiliki pengaruh cukup kuat. Nilai adjusted R Square sebesar 0.194 atau (20\%). Hal ini menunjukkan bahwa persentase status kepegawaian terhadap kinerja pegawai sebesar 20\%, sedangkan sisanya sebesar $80 \%$ dipengaruhi oleh variabel lain diluar variabel yang diteliti.

\section{UCAPAN TERIMAKASIH}

Ucapan terima kasih penulis sampaikan kepada semua pegawai Kantor Kesejahteraan Rakyat Mandailing Natal, yang telah bersedia memberikan informasi terkait penelitian penulis. Sehingga, penelitian ini dapat selesai dengan baik, lancer, dan sukses.

\section{REFERENSI}

Abdullah, Rasyidin \& Azis, M. (2019). Puskesmas Kajuara in Bone Regency YUME : Journal of Management. 2(1).

Africa, S., Development, S. A., Acyl, F., Free, T., Area, T., Summit, T., Committee, T. S., Tfta, T., Community, E. A., African, S., Community, D., Market, C., Africa, S., Africa, S., Union, A., Tfta, T., Fta, G., Summit, T., Secretary, C., ... Summary, E. (2020). Pengaruh sistem informasi manajemen kepegawaian (simpeg) terhadap kualitas pelayanan administras pegawai di dinas pendidikan kota solok. Human Relations, http://search.ebscohost.com/login.aspx?direct=true\& $\&$ Auth

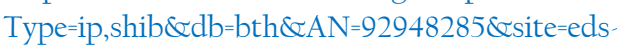

live\&scope=site\%0Ahttp://bimpactassessment.net/sites/all /themes/bcorp_impact/pdfs/em_stakeholder_engagement.p df\%0Ahttps://www.glo-bus.com/help/helpFiles/CDJ-Pa

Anjanarko, T. S., \& Kurlilah, A. (2020). Pengaruh Status Kepegawaian, Kompetensi Karyawan dan Budaya Organisasi Terhadap Kinerja Karyawan di Gedung PT. Mitra Pinasthika Mulia Sidoarjo. Jurnal Bisnis Dan Manajemen, 4(1), 48-68.

Arikunto, S. (2009). Prosedur Penelitian Suatu Pendekatan Praktik Edisi Revisi 6. Rineka Cipta.

Fay, D. L. (1967). Kinerja Pegawai Negeri Sipil (PNS) Di Kantor Badan Kepegawaian Daerah Kabupaten Kutai Timur Dirk Malaga Kusuma. Angewandte Chemie International Edition, 6(11), 951-952., 1388-1400.

Haridsyah. (2018). Pengaruh Perbedaan Status Terhadap Kinerja Pegawai Di Kantor Kecamatan Panyabungan Utara. Sumatera Utara.

Hendrajana, I. G. M. R., Sintaasih, D. K., \& Saroyeni, P. (2017). Analisis Hubungan Status Kepegawaian, Komitmen Organisasional dan Kinerja Karyawan. E-Jurnal Ekonomi Dan Bisnis Universitas Udayana, 1, 357-384.

Jeneponto, C. (2020). Kontrak (Studi Kasus Pada Pt. Bank Sulselbar SkripsiOleh EstiNur.

Mursyidin. (2020). Pengaruh Pemberian Penghargaan Terhadap Kinerja Pegawai Di Dinas Kebudayaan Dan Pemuda Kabupaten Aceh Barat. Paper Knowledge. Toward a Media History of Documents, 12-26.

Murti, H., \& Srimulyani, V. A. (2013). Pengaruh Motivasi Terhadap Kinerja Pegawai Dengan Variabel Pemediasi Kepuasaan Kerja Pada Pdam Kota Madiun. JRMA Jurnal Riset Manajemen Dan Akuntansi, 1(1), 10-17.

Pangarso, A., \& Susanti, P. I. (2016). Pengaruh Disiplin Kerja Terhadap Kinerja Pegawai Di Biro Pelayanan Sosial Dasar Sekretariat Daerah Provinsi Jawa Barat. Jurnal Manajemen Teori Dan Terapan| Journal of Theory and Applied Management, 9(2), 145-160. https://doi.org/10.20473/jmtt.v9i2.3019

Taruangi, H. F. (2009). IMPLEMENTASI KEBIJAKAN TUNJANGAN KHUSUS GURU DAERAH. 41, 43-52.

Akselaran.co.id. (2020). Ini Dampak Perkembangan Teknologi Yang Dapat Dirasakan. http://www.akseleran.co.id/blog/perkembangan-teknologi/ Diakses pada 30 mei 2021 08:00 wib. 